Research Article

\title{
Noise Exposure and its Relationship with Hypertension among Fishermen in Thua Thien Hue Province, Vietnam
}

\author{
Nhan Phuc Thanh Nguyen ${ }^{1,2}$, Duong Dinh Le ${ }^{3,6}$, Man Dinh Minh Nguyen ${ }^{3}$, \\ Ai Ha Phan Nguyen ${ }^{4}$, Bao Van Anh Ha ${ }^{5}$, Huan Minh Tran ${ }^{1,5}$, Nam Tran Ton Nu ${ }^{3}$, \\ Nontiya Homkham', Twisuk Punpeng' \\ ${ }^{1}$ Faculty of Public Health, Thammasat University (Rangsit Center), Khlong Luang, Pathum Thani, 12121, Thailand. \\ ${ }^{2}$ Institute for Community Health Research, Hue University of Medicine and Pharmacy, Hue University, Vietnam. \\ ${ }^{3}$ Hue University of Medicine and Pharmacy, Hue University, Vietnam. \\ ${ }^{4}$ Institute of Public Health, Ministry of Health, Vietnam. \\ ${ }^{5}$ Da Nang University of Medical Technology and Pharmacy, Vietnam. \\ ${ }^{6}$ Faculty of Public Health, Khon Kaen University, Thailand. \\ DOI: https://doi.org/10.24321/2319.9113.202001
}

\section{I $\quad \mathbf{N} \quad \mathbf{F} \quad \mathbf{O}$}

\section{Corresponding Author:}

Nhan Phuc Thanh Nguyen, Faculty of Public Health, Thammasat University (Rangsit Center), Khlong Luang, Pathum Thani, 12121, Thailand \& Institute for Community Health Research, Hue University of Medicine and Pharmacy, Hue University, Vietnam.

E-mail Id:

nptnhan@huemed-univ.edu.vn

Orcid Id:

https://orcid.org/0000-0001-8826-9757

How to cite this article:

Nhan Nguyen, Duong D Le, Man DM Nguyen, Ha PA Nguyen, Bao VA Ha, Huan M Tran et al. Noise Exposure and its Relationship with Hypertension among Fishermen in Thua Thien Hue Province, Vietnam. J Integ Comm Health 2020; 9(1): 3-16.

Date of Submission: 2020-03-05

Date of Acceptance: 2020-06-11

\section{$\begin{array}{llllllll}\mathbf{A} & \mathbf{B} & \mathbf{S} & \mathbf{T} & \mathbf{R} & \mathbf{A} & \mathbf{C} & \mathbf{T}\end{array}$}

Introduction: Fishermen work in an unfavorable working environment, which faces many disadvantages such as inclement weather conditions, prolonged working time with hard labor and are effected by adverse environmental factors, in which noise is the most common agent but there are very few studies on the effects of noise to fishermen's health especially on blood pressure.

Methodology: A cross-sectional study was conducted on 159 fishermen who were working in 14 offshore ships, a sound level meter was used for noise measurement and the noise exposures were calculated based on the average working time in 8 hours. Questionnaires were used for interviewing, blood pressure was measured by trained local doctors.

Result: It was found that $71.1 \%$ fishermen were expose to the working noise which is over $85 \mathrm{dBA}$ for 8 working hours a day. The highest average sound level was recorded in the engine room (min-max: 91.896.2), follow by driving cabin (min-max: 83.1-92.2). Blood pressure measurements showed a result of $28.9 \%$ hypertensive fishermen. There was not statistically significant between hypertension and exposure to noise.

Conclusions: It can be concluded that almost three quarters of the fishermen exposed to noise in the working environment exceeds 85 $\mathrm{dBA}$ for 8 hours. Futher studies are required to provide comprehensive approach between noise and hypertension.

Keywords: Fishermen, Noise Exposure, TWA8, Hypertension 


\section{Introduction}

The working environment on the ship contains many hidden risks to workers's health. Working in inclement weather conditions such as the severe climate on the sea, the sun, the sea breeze, the waves affect workers' health. ${ }^{1}$ Furthermore, noise, vibration, cramped workspace, unsanitary conditions, lack of nutrition and limited healthcare are creation of working environment taking into specific characteristics of the marine exploitation. ${ }^{2}$ Some studies also have shown unreasonable diet, lack of physical activity as well as the issues related to ergonomics lead to accidents, the problems of muscle-skeleton, stress, cardiovascular disease that fishermen often encounter. ${ }^{1,3}$ Among above factors, noise is one of the most influential factors on the health of fishermen.

Exposure to noise for a long time leads to disadvantageous effects on workers's health. Exposure to excessive noise in the labor process is a common problem in the industry, including the aquatic fisheries industry. ${ }^{4}$ The noise appears regularly and continuously throughout the sea voyage and even when parking at the pier with many different levels. Some positions on fish vessels such as machine chambers, control rooms have higher noise intensity than usual, mainly in high frequency range. Exposure for a long time will have not only hearing effects such as hearing loss, deafness, tinnitus, but also cardiovascular pathologies, stress, sleep disorders. ${ }^{5-7}$ These affect the fishermen's health and are associated with a reduction in the overall quality of life. ${ }^{8}$ Under of noise influence, endocrine glands have some impact on blood pressure, the increase of heart rate and as well as other hormones such as cortisol, norepinephrine, adrenaline (epinephrine). ${ }^{9,10}$

In Vietnam, some researches on noise pollution have been published in recent years but focus has been mainly on noise intensity or loss of hearing. Only in recent years, the research on the health impacts due to the new industrial noise is focused but it is still very few and on small scale. In addition, the implementation of research such as sampling at long-shore fishing vessels is a hindback to researchers due to the source of information, limited data as well as protection measures, healthcare policies while this is an extremely important group of people for social-economic development, the protection of the sea and sovereignty of the national island. That sets out the needs of studying the impacts of the labor environment on the health of fishermen to provide the evidence for policy-making and to make more effective measures in protecting fishermen's health care. In terms of noise and its influence, determining the proportion of the fishermen who are working under high noise environment ( $>85 \mathrm{dBA}$ ) and the effects on the health would provide useful information for subsequent intervention programs.

\section{Methodology}

\section{Study Design and Participants}

A cross-sectional study was carried out from August 2018 to May 2019 in Thua Thien Hue province, a Vietnam-coastal province with $120 \mathrm{~km}$ of coastline.

Participants were selected based on a list of fishermen who were working in offshore fishing ship (engine power $\geq 400$ HP) provided by local government. A total 159 fishermen were estimated to participate in the research. The criteria for selectionwas over 18 years old age, at least 12 months of work experience, absence of acute health problems and voluntary participant. Exclusion criteria were workers whose ages are lower than eighteen ${ }^{18}$ years and work experience less than twelve (12) months and those who did not agree to participate.

\section{Data Collection \\ Data Collection Process}

Based on management data of local government, there were 1314 offshore fishing ship (engine power $>400 \mathrm{HP}$ ) and 121 fishing ships in research area. The number of employees in a ship normally range from 10 to 12 . Then, 11 to 15 fishing ships was chosen until there were at least 151 fishermen. Sound Pressure Level (SPL) in the chosen ships was measured. Finally, fishermen were interviewed with structured questionnaire and blood pressure index was measured.

\section{Data collection Technique}

\section{Noise Measument}

Sound Pressure Level (SPL) was measured continuously for about 5-minute periods at each location and $\mathrm{L}_{\mathrm{eq}}(\mathrm{dBA})$ was recorded. This duration was decided according to ISO 9612 standard method, although a minimum of 10-s period was recommended by IMO (1982) and other shorter measurement periods were used in previous studies. ${ }^{11}$

Sound Level Meter Class 1 Rion NL-52 were used for noise measurement in this research. Device was set up with Scale A or A-weighting, Slow response, Exchange rate $3 \mathrm{~dB}$. Rain protection windscreen WS-16 (attach with Rion NL-52) were used to reduce effect of sea wind during data collection. SPL was calibrated every 2 years by Center for Quality Measurement Standards Technology; SLP was tested with sound calibrator before using in fishing ship.

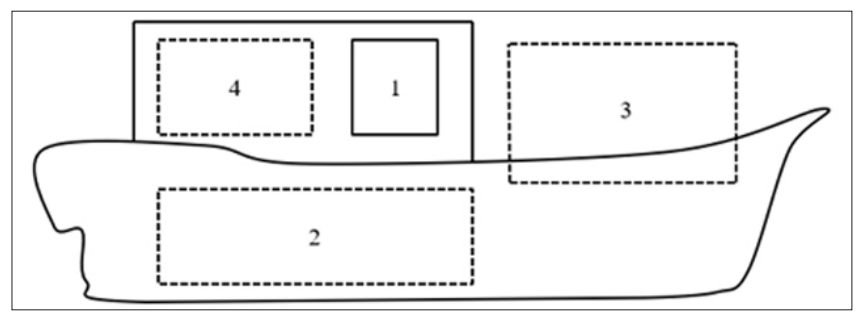




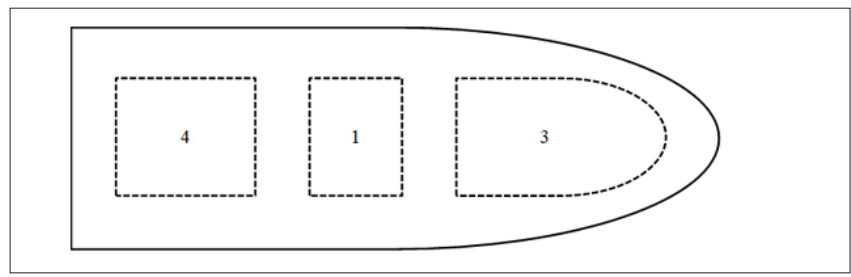

Figure I.Common structure of offshore fishing ship in research area. (I) Driving cabin, (2) Engine room, (3) Deck, (4) Resting area

Table I.Description of sound pressure measurement locations

\begin{tabular}{|c|c|c|}
\hline S. No. & Location & Types of work \\
\hline 1. & Driving cabin & $\begin{array}{c}\text { Surveillance and driving, only } \\
\text { captain take responsibility. }\end{array}$ \\
\hline 2. & Engine room & $\begin{array}{c}\text { Involves activities such as } \\
\text { turning the engine on and off, } \\
\text { checking and lubricating the } \\
\text { engine ... There is no worker } \\
\text { for most of time, workers } \\
\text { come to work for a short time } \\
\text { and leave the room. }\end{array}$ \\
\hline 3. & Deck & $\begin{array}{c}\text { Net repairing, collecting fish } \\
\text { and place for sitting during } \\
\text { resting or waiting time. }\end{array}$ \\
\hline 4. & Resting area & $\begin{array}{c}\text { Sleeping, eating and resting } \\
\text { while they have no work. }\end{array}$ \\
\hline
\end{tabular}

\section{Hypertension Measurement}

According the criteria of World Health Organization, hypertension was defined based on the average Systolic Blood Pressure (SBP) $\geq 140 \mathrm{mmHg}$ and/ or average Diastolic Blood Pressure (DBP) $\geq 90 \mathrm{mmHg}$ and/ or selfreported previous diagnosis of hypertension by a health professional. ${ }^{12}$ In this research, blood pressure was measured by physician with standard evaluation in sitting position after five minutes resting. The measurement was conducted before the offshore trip to avoid temporary hypertension or some changing in blood pressure during or after offshore trip. Blood pressure was measured twice and if the BP recorded were different by 5 points or more, a third time would be done.

\section{Noise Calculation}

Noise exposure calculation was conducted according to the recommended NIOSH standard for occupational noise exposure with time weighted average $85 \mathrm{dBA}$ for 8 hours work shift using $3 \mathrm{~dB}$ exchange rate for longer exposure period. ${ }^{13}$ With exposure level $\mathrm{L}_{\mathrm{eq}}$ of each position, the permissible duration in this position was calculated by this formula:

$$
\mathbf{T}_{\mathbf{p}}=\frac{\mathbf{8}}{\mathbf{2}^{(\text {Leq-85)/3}}} \text { hour }
$$

$T_{p}$ : permissible exposure duration (hour).

$\mathrm{L}_{\mathrm{eq}}$ : measured sound level (dBA).

Each fishermen's exposure with different noise level in different position during their work shift and longer than 8 hours in NIOSH standard, the noise level $\left(\mathrm{L}_{\text {eq }}\right)$ was calculated by this formula:

$$
\mathrm{L}_{\mathrm{eq}, \mathrm{T}}=10^{*} \log \left(\frac{1}{\mathrm{~T}} *\left(\mathrm{t}_{1} \times 10^{0.1^{*} \text { Leq } 1}+\ldots .+\mathrm{t}_{\mathrm{n}} \times 10^{0.1^{*} \text { Lequ }}\right)\right) \mathrm{dBA}
$$

T: total time of exposure in hour.

Leq: measured sound level (dBA).

$\mathrm{n}$ : number of discrete job.

After obtaining sound pressure data during shift in $\mathrm{T}$ (hour), the data were transferred to daily personal noise exposure based on 8-hours $\left(\mathrm{L}_{\mathrm{ex}, 8}\right)$ with this following formula:

$$
\mathbf{L}_{\mathrm{ex}, 8}=\mathbf{L}_{\mathrm{eq}, \mathrm{T}}+\mathbf{1 0} \log \frac{T}{8}
$$

T: total time of exposure in hour [from formula (2)].

When the daily noise exposure consisted of periods of different noise levels, the daily dose (D) were not equal or exceeded 100, as calculated according to the following formula:

$\mathrm{D}=\frac{c_{1}}{T_{1}}+\frac{c_{2}}{T_{2}}+\cdots+\frac{c_{n}}{T_{n}} \quad * 100 \%$

where

$\mathrm{C}_{\mathrm{n}}=$ total time of exposure at a specified noise level,

$\mathrm{T}_{\mathrm{n}}=$ exposure duration for which noise at this level becomes hazardous. (using formula (1)).

The daily dose was converted into an 8 hour Time Weighted Average noise levels (TWA8) according to the following formula:

$$
\text { TWA }=10 \times \log \frac{\text { Dose }}{100}+85 \quad \mathrm{dBA}
$$

\section{Statistical Analysis}

In univariate analysis, baseline characteristics were compared with hypertension of fishermen by appropriate testing. Occupational noise dose was presented followed by the standardized formula in 8 hours TWA. Multiple logistic regression model with Generalize Estimating Equation (GEE) was applied to adjustment the association between exposed noise level and hypertension. In the fitting model, we conducted the GEE for adjustment in the ships, the associated noise volume and hypertension was modified with working time, body mass index, salty diets, alcohol abuse and family history with HP.

\section{Result}

\section{Characteristics of Participants and Hypertension Prevalence}

Data from 159 fishermen in 14 fishing ship were included in 
our analysis. Prevalence of hypertension was approximately $28.9 \%$ (46/159) (Table 2). All fishermen were over 30 years olds and had at least 10 years working in current fishing ship. Most of their age was in 40-49 (97/159) with 10 to 20 experience years (85/159). 45.2\% (72/159) participants attained primary level and below, and only $18.9 \%$ (30/159) had high school and higher education level.

$45.2 \%$ were overweight based on BMI criteria for Asian ( $\geq$ $23 \mathrm{~kg} / \mathrm{m}^{2}$ ) but there were no statistical significance between hypertension and BMI index.

On lifestyle behaviors, prevalence of hypertension was higher among participants who was currently smoking, using alcohol at harmful level and having salty diet compared with normal group $(p<0.001)$

\section{Sound Pressure at Measument Locations}

The highest sound level was recorded in Engine room area, where the lowest was $91.8 \mathrm{dBA}$, and the highest was 96.2 dBA (Figure 2). The second area with a high sound level was the Driving cabin where the lowest level was $83.1 \mathrm{dBA}$ and the highest level was $92.2 \mathrm{dBA}$. The highest sound level in Deck area was $86.1 \mathrm{dBA}$ and the lowest was $80.9 \mathrm{dbA}$. In resting area, the highest sound level was $87.7 \mathrm{dBA}$ and $81.3 \mathrm{dBA}$ was the lowest sound level.

\section{Noise Exposure Level}

Table 3 shows that there were 113 fishermen, making up $71.1 \%$, bearing the working noise which was over $85 \mathrm{dBA}$ for eight working hours a day (TWA $8>85 \mathrm{dBA}$ ), according to the recommendations of $\mathrm{NIOSH}$.

Table 2.Baseline characteristics of fishermen by level hypertension

\begin{tabular}{|c|c|c|c|}
\hline Variable & Hypertension n (\%) & Normotensive $\mathrm{n}(\%)$ & p-value* \\
\hline \multicolumn{4}{|c|}{ Age (years) } \\
\hline $30-39$ & $7(14.3)$ & $42(85.7)$ & \multirow{4}{*}{0.024} \\
\hline $40-49$ & $34(35.1)$ & $63(64.9)$ & \\
\hline$\geq 50$ & $5(38.5)$ & $8(61.5)$ & \\
\hline Mean \pm SD & & & \\
\hline \multicolumn{4}{|c|}{ Currently experience year } \\
\hline$<10$ years & $3(6.7)$ & $42(93.3)$ & \multirow{3}{*}{$<0.001$} \\
\hline $10-20$ years & $27(31.8)$ & $58(68.2)$ & \\
\hline$>20$ years & $16(55.2)$ & $13(44.8)$ & \\
\hline \multicolumn{4}{|c|}{ Highest level of education attained } \\
\hline Iliteracy and Primary school & $27(37.5)$ & $45(62.5)$ & \multirow{3}{*}{0.041} \\
\hline Junior high school & $17(29.8)$ & $40(70.2)$ & \\
\hline High school and higher & $2(6.7)$ & $28(93.3)$ & \\
\hline \multicolumn{4}{|c|}{ Body Mass Index $\left(\mathrm{kg} / \mathrm{m}^{2}\right)$} \\
\hline Normal (<23) & $22(25.3)$ & $65(74.7)$ & \multirow{2}{*}{0.295} \\
\hline Overweight $((\geq 23.0)$ & $24(33.3)$ & $48(66.7)$ & \\
\hline \multicolumn{4}{|c|}{ Current Smoking } \\
\hline Yes & $37(41.1)$ & $53(58.9)$ & \multirow{2}{*}{$<0.001$} \\
\hline No & $9(13.0)$ & $60(87.0)$ & \\
\hline \multicolumn{4}{|c|}{ Alcohol Abuse (>2 units/day) } \\
\hline Abuse & $19(65.5)$ & $10(34.5)$ & \multirow{2}{*}{$<0.001$} \\
\hline Normal & $27(20.8)$ & $103(79.2)$ & \\
\hline \multicolumn{4}{|c|}{ Salty diet (>5g salt $\sim 1$ teaspoon/day) } \\
\hline Salty diet & $32(50.8)$ & $31(49.2)$ & \multirow{3}{*}{$<0.001$} \\
\hline Normal & $14(14.6)$ & $82(85.4)$ & \\
\hline Total & $46(28.9)$ & $113(71.1)$ & \\
\hline
\end{tabular}

* p-value from Chi-square test 


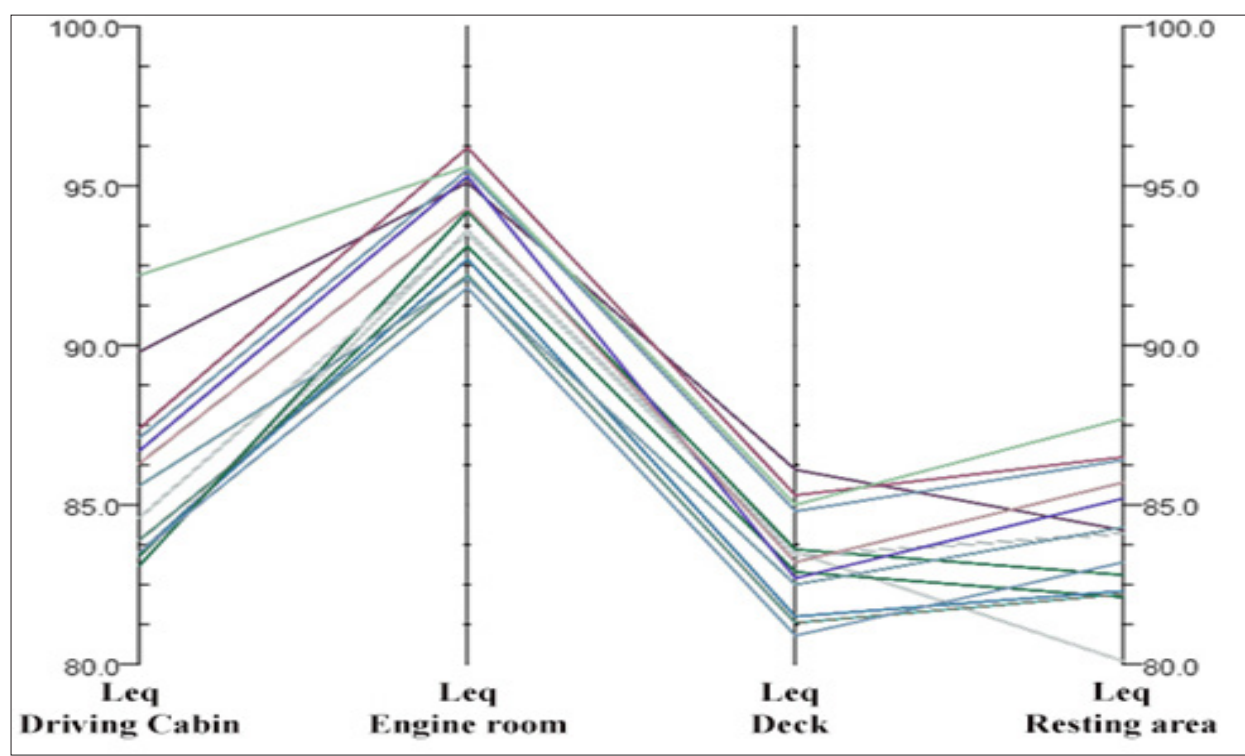

Figure 2.Noise level in measurement locations

Table 3.Time weighted average 8 hours of fishermen

\begin{tabular}{|c|c|c|c|}
\hline \multicolumn{2}{|c|}{ Characteristic } & $\mathbf{n}$ & Prevalance \% \\
\hline \multirow{2}{*}{ Exposure level } & TWA 8 > 85 dBA & 113 & 71.1 \\
\cline { 2 - 4 } & TWA_8 $\leq 85 \mathrm{dBA}$ & 46 & 28.9 \\
\hline Average exposure time daily & Mean \pm SD (hour) & $12.3 \pm 0.61$ & \\
\hline & Range: min - max (hour) & $11-14$ & \\
\hline
\end{tabular}

Table 4.Logistic regession model with generalized equation estimating to explain the hypertension on fishermen

\begin{tabular}{|c|c|c|c|}
\hline Factor & Crude OR $(95 \% \mathrm{Cl})$ & Adj. OR (95\% Cl) & p \\
\hline TWA-8hours & $1.403(1.163-1.693)$ & $1.212(0.981-1.497)$ & 0.075 \\
\hline Experience (years) & 1.129 (1.072-1.189) & 1.069 (1.007-1.136) & 0.028 \\
\hline Body mass index $\left(\mathrm{kg} / \mathrm{m}^{2}\right)$ & $1.190(0.992-1.426)$ & $1.279(1.026-1.595)$ & 0.029 \\
\hline \multicolumn{4}{|l|}{ Salty diets } \\
\hline No & Ref. & Ref. & \\
\hline Yes & $6.046(2.851-12.823)$ & $2.482(0.996-6.187)$ & 0.051 \\
\hline \multicolumn{4}{|l|}{ Alcohol abuse } \\
\hline Not abuse & Ref. & Ref. & \\
\hline Abuse & $7.248(3.021-17.390)$ & $2.827(0.979-8.163)$ & 0.055 \\
\hline \multicolumn{4}{|c|}{ Family history with hypertension } \\
\hline No & Ref. & Ref. & \\
\hline Yes & $7.071(3.163-15.809)$ & $2.768(1.054-7.268)$ & 0.039 \\
\hline
\end{tabular}

Relationship between Noise Exposure and Hypertension

In the fitting logistic regression model, experience years in current fishing ship, body mass index and family history with hypertension were contributed to explain the relationship with hypertension. The result showed that there was insignificant difference between TWA-8 hours, salty diets, alcohol abuse and outcomes (Table 4).

\section{Discussion}

\section{Noise Exposure Level}

In this research, working time of fishermen on the ship was 
not fixed, lasted more than 8 hours a day and inconsistently on 14 ships. Therefore, formulas in "Noise Calculation" section given earlier were used to determine the TWA-8 hours of fishermen in this research and results showed that approximately 3 of 4 employees (71.1\%) had the adverse noise dose, TWA- 8 hours over 85 dBA (Table 3). Working in the environment where TWA 8 exceeds $85 \mathrm{dBA}$ means the noise was in harmful level and it would lead to some harmful effects on health such as hearing reduction, deafness or non-auditory effect such as annoyance, sleep disturbance, increased the occurrence of hypertension and cardiovascular disease. ${ }^{4-6}$

\section{Hypertension}

Based on blood pressure measurement, hypertension prevalence was $28.9 \%$. This prevalence was higher than average prevalence of Vietnamese adults in "National survey of risk factors for non-communicable diseases" in 2015 with $18.9 \% .{ }^{14}$ The reason of these differences could be the diagnosis cut-off point and different characteristics of participants in the research. In national survey, they used cut-off point for hypertension diagnosis $140 \mathrm{mmHg}$ systolic or $90 \mathrm{mmHg}$ disastolic, higher than $130 / 80$ in this research and it leads to higher prevalence of hypertension in this research. Besides, fishermen's exposure with many risk factors for hypertension such as salty diet; alcohol, tobacco consumption at abuse level could have contributed to the results in this study. ${ }^{15,16}$

Comparing with the previous literature, hypertenstion of fishermen varied worldwide from $15 \%$ to $70 \%$. We found that hypertension prevalence varies in different countries, such as $24.5 \%$ in Indian research or only $15 \%$ hypertensive fishermen in Nigerian research on 400 fishermen. ${ }^{17,18}$ Our results were lower than hypertension among Danish seafarers (44.7\%). This could be due to the different characteristic of Asian and Nordic people. ${ }^{19}$ In our study, compared with research in Brazil with fishermen who were over 40 years old, the prevalence of hypertensive participants was extremely higher, with $70 \% .{ }^{20}$ This difference is understandable because hypertension risk increases with age; higher age is associated with higher risk of hypertension and vice versa. ${ }^{21-23}$

\section{Relationship between Noise Exposure and Hypertension}

Result in Table 4, showed that there was insignificant difference between noise exposure and hypertension. Several hypotheses mentioned relation between exposure with noise at harmful level and increased blood pressure index leads to hypertension, but epidemiological evidence was still limited. Many standpoints supported or opposed this hypothesis with specific studies.
On this research results, several reasons could explain these issues; limitation in sample size was one of some acceptable reasons. Beside it, lack of noise dosimeter, error during sound measurement and exposure time report as well as absence of individual confounder data, adds to the risk of bias could affect to research results. In fact, opinions on weak relationship between noise exposure and hypertension or argument that noise only caused the increase in blood pressure and did not lead to hypertension as well as no significant relationship between two variables were mentioned in several researches. ${ }^{24-27}$

On the other hand, opinion of not having statistically significant relation between noise and hypertension was given by several researchers. Gan et al. proved the evidence was not consistent to support the association between occupational noise exposure and blood pressure after conducting research in 4,548 participants. ${ }^{28}$ After reviewing 43 epidemiologic studies on noise exposure and cardiovascular diseases, another author suggested that noise exposure could contribute to the prevalence of cardiovascular disease but evidence of this relationship was still inconclusive because of confounder bias ${ }^{29}$ or an idea on no significant difference in blood pressure and heart rate before and after the exposure from research on 50 workers in a steel company. ${ }^{30}$

\section{Conclusion and Recommendation}

In conclusion, majority of fishermen working on offshore fishing ship in Thua Thien Hue province were exposed to noise in harmful level. It is recommended to apply some engineering controls to reduce noise's harmful. Solution could be building bulkhead, doors or replace old wall with sound insulation materials between Engine room and nearby locations; re-design the exhaust pipes far from the captain's cabin area to reduce the noise from Engine room. Administrative control may include reschedule of working hours to reduce the exposure to high noise level and increase the exposure to low noise levels such as resting area or front deck for crew members at location with high noise levels. However, it is not feasible for applying the reschedule of working hours to the captains and mechanics who spend almost their time in the Engine room. Therefore, PPE including earplugs effectively reduce the noise impact for them despite its limitation on verbal communication is essential for the captains and mechanics.

Prevalence of hypertension in fishermen was at a high level when comparing to other occupations. Changing lifestyle behavior is essential to minimize this issue. Although relationship between hypertension and TWA8> $85 \mathrm{dBA}$ was not found because many factors could impact blood pressure, such as age and years of experience but the harmful effects of continued exposure to noise for a 
long time could not be denied. Further follow up studies which apply noise dosimeter are needed to provide a comprehensive on this relationship.

\section{Limitation}

The study had various limitations which might have implications to research results. Data was collected on the sea during offshore trip which took a long time and noise dosimeter could not be used for noise measuring. These could reduce data's accuracy. Some minor changes in ship and wind speed could lead to changes in noise measurement and, finally, some questions could be affected by recall bias.

\section{Acknowledgement}

I send my gratitude to Director Board in Phu Vang District Health Center, Mr. Than Minh Tri, Mr. Nguyen Hoang Minh, ship captain Nguyen Thanh Do and his sister

Mai Nguyen for their support in data collection. Finally, my deepest acknowledgements are sent to family for their unconditional support.

\section{Conflict of Interest: None}

\section{References}

1. Sønvisen SA, Thorvaldsen T, Holmen IM, Øren A. Work environment and health in the fishing fleet: results from a survey amongst Norwegian fishers. International maritime health 2017; 68(4): 203-210.

2. Mahmoud El-Saied El-Saadawy NE-LS, Ihab Mohammadi Mohamed El-Tayeb, Marehan Ahmed Hammouda. Some occupational health hazards among fishermen in Alexandria city. Gaziantep Medical Journal 2014; 20(1).

3. Østergaard H, Jepsen JR, Berg-Beckhoff G. The workload of fishermen: a cross sectional survey among Danish commercial fishermen. International maritime health 2016; 67(2): 97-103.

4. Md Tamrin S, Latifi Naeini R. The Prevalence of Occupational Stress as a Non-Auditory Effect of Noise among Palm Oil Mill Workers in 7 Sections of Two Selected Mills. Asian Journal of Medical and Pharmaceutical Researches 2014; 4: 78-84.

5. Anne Carroll SC, Henry F, Mellor G, Gliddon A, Langford $D$, Davis $G$. The health effects of environmental noise - other than hearing loss. 2004.

6. Basner M, Babisch W, Davis A, Brink M, Clark C, Janssen $S$ et al. Auditory and non-auditory effects of noise on health. Lancet 2014; 383(9925): 1325-1332.

7. Ristovska G, Lekaviciute J. Environmental noise and sleep disturbance: research in Central, Eastern and South-Eastern Europe and Newly Independent States. Noise \& health 2013; 15(62): 6-11.

8. Bright Otoghile PAO, Confidence C. Otoghile. Effects of occupational noise on quality of life. International
Journal of Otorhinolaryngology and Head and Neck Surgery 2018; 4(5).

9. Babisch W. Stress hormones in the research on cardiovascular effects of noise. Noise \& health 2003; 5(18): 1-11.

10. Selander J, Nilsson ME, Bluhm G, Rosenlund M, Lindqvist $\mathrm{M}$, Nise $\mathrm{G}$ et al. Long-term exposure to road traffic noise and myocardial infarction. Epidemiology (Cambridge, Mass) 2009; 20(2): 272-279.

11. Zytoon MA. Occupational noise exposure of fishermen aboard small and medium-scale fishing vessels. International Journal of Industrial Ergonomics 2013; 43(6): 487-494.

12. WHO. Hypertension 2015 [Available from: https:// www.who.int/health-topics/hypertension/.

13. NIOSH. Criteria for a recommended standard: occupational noise exposure. Revised criteria 1998 Cincinnati, $\mathrm{OH}$, National Institute for Occupational Safety and Health1998 [Available from: https://www. cdc.gov/niosh/docs/98-126/default.html.

14. WHO. Viet Nam National STEPS Survey 20152015 [Available from: https://www.who.int/ncds/un-taskforce/steps-survey-vietnam2015.pdf.

15. Aslami AN, Jobby A, Nelson V, Simon S. Prevalence of hypertension in a fishermen colony of district Kollam, Kerala: A cross-sectional study. Research Journal of Pharmaceutical, Biological and Chemical Sciences 2015; 6: 1029-1035.

16. Woodhead AJ, Abernethy KE, Szaboova L, Turner RA. Health in fishing communities: A global perspective. Fish and Fisheries 2018; 19(5): 839-852.

17. Aslami AN, Jobby A. Compliance to Hypertension Treatment in Residents of a Fishermen Colony in District Kollam, Kerala. Nepal journal of epidemiology 2015; 5(2): 480-487.

18. Suleiman IA, Amogu EO, Ganiyu KA. Prevalence and control of hypertension in a Niger Delta semi urban community, Nigeria. Pharmacy practice 2013; 11(1): 24-29.

19. Tu M, Jepsen JR. Hypertension among Danish seafarers. International maritime health 2016; 67(4): 196-204.

20. Begossi B. Blood Pressure and Hypertension among Coastal Fishermen in South-east Brazil. Journal of Community Medicine \& Health Education 2013; 04.

21. Borzecki AM, Glickman ME, Kader B, Berlowitz DR. The Effect of Age on Hypertension Control and Management*. American Journal of Hypertension 2006; 19(5): 520-527.

22. Gurven M, Blackwell AD, Rodríguez DE, Stieglitz J, Kaplan H. Does blood pressure inevitably rise with age?: longitudinal evidence among forager-horticulturalists. Hypertension (Dallas, Tex : 1979) 2012; 60(1): 25-33.

23. Whelton PK, Carey RM, Aronow WS, Casey DE, Collins 
KJ, Dennison Himmelfarb C et al. 2017 ACC/AHA/ AAPA/ABC/ACPM/AGS/APhA/ASH/ASPC/NMA/PCNA Guideline for the Prevention, Detection, Evaluation, and Management of High Blood Pressure in Adults. Journal of the American College of Cardiology 2018; 71(19): e127.

24. Assunta C, Ilaria S, Simone de S, Gianfranco T, Teodorico $C$, Carmina $S$ et al. Noise and cardiovascular effects in workers of the sanitary fixtures industry. International journal of hygiene and environmental health 2015; 218(1): 163-168.

25. Dratva J, Phuleria HC, Foraster M, Gaspoz JM, Keidel D, Künzli N et al. Transportation noise and blood pressure in a population-based sample of adults. Environmental health perspectives 2012; 120(1): 50-55.

26. Kalantary S, Dehghani A, Yekaninejad MS, Omidi L, Rahimzadeh $M$. The effects of occupational noise on blood pressure and heart rate of workers in an automotive parts industry. ARYA atherosclerosis 2015; 11(4): 215-219.

27. Sørensen M, Hvidberg M, Hoffmann B, Andersen ZJ, Nordsborg RB, Lillelund KG et al. Exposure to road traffic and railway noise and associations with blood pressure and self-reported hypertension: a cohort study. Environmental health : a global access science source 2011; 10: 92.

28. Gan WQ, Mannino DM. Occupational Noise Exposure, Bilateral High-Frequency Hearing Loss, and Blood Pressure. Journal of occupational and environmental medicine 2018; 60(5): 462-468.

29. Van Kempen EE, Kruize H, Boshuizen HC, Ameling CB, Staatsen BA, de Hollander AE. The association between noise exposure and blood pressure and ischemic heart disease: a meta-analysis. Environmental health perspectives 2002; 110(3): 307-317.

30. Zamanian Z, Rostami R, Hasanzadeh. Investigation of the effect of occupational noise exposure on blood pressure and heart rate of steel industry workers. Journal of environmental and public health 2013. 


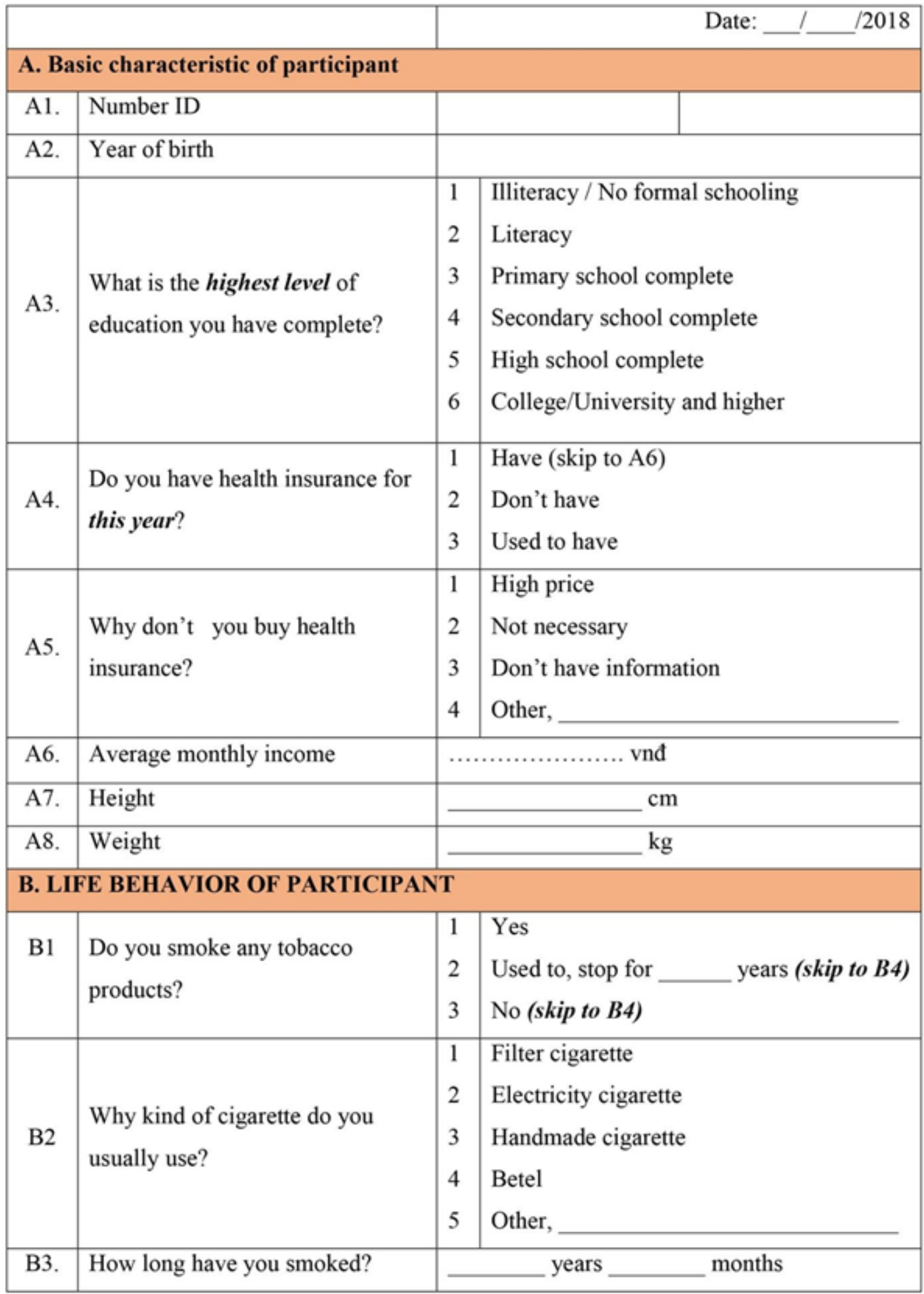




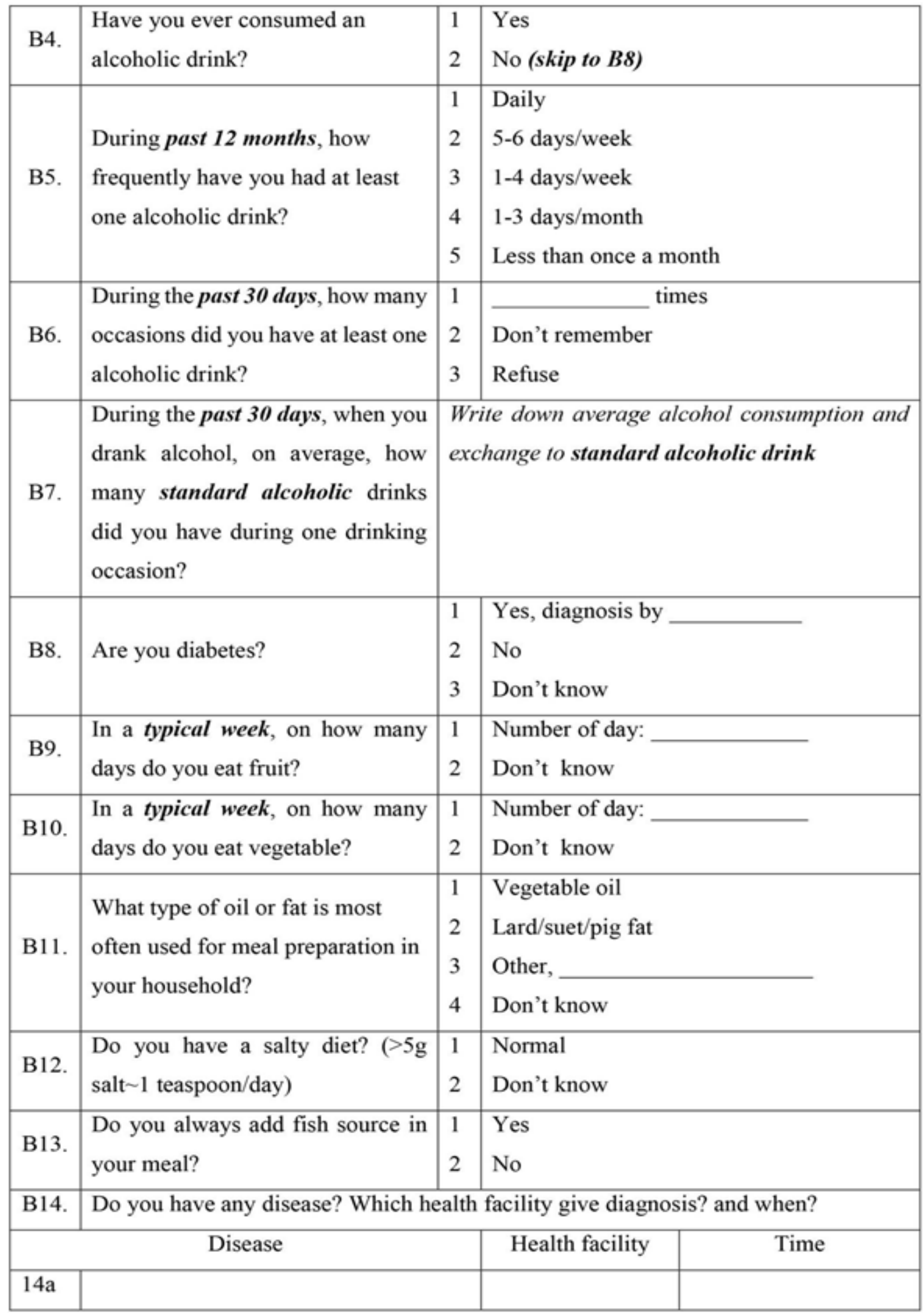




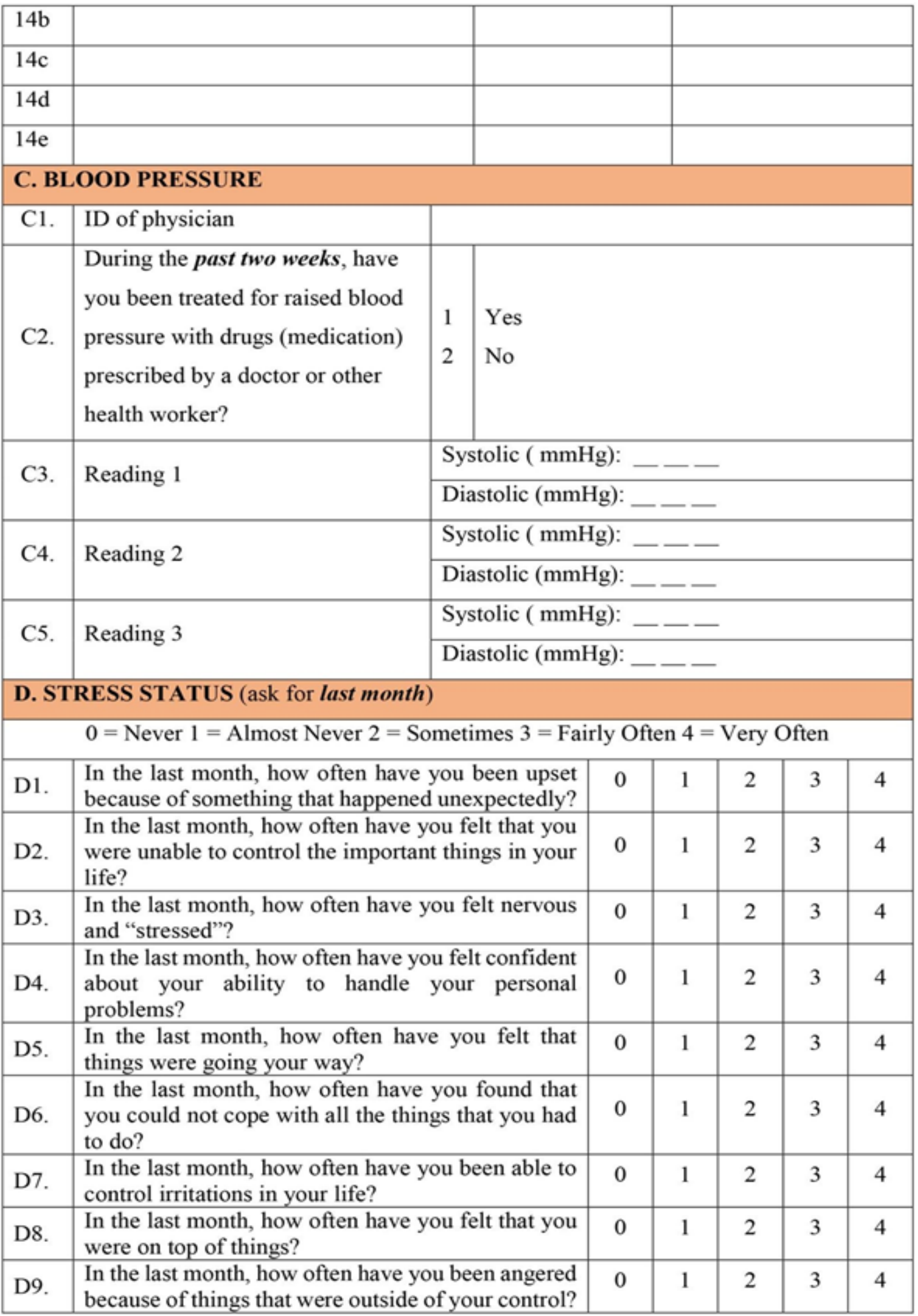




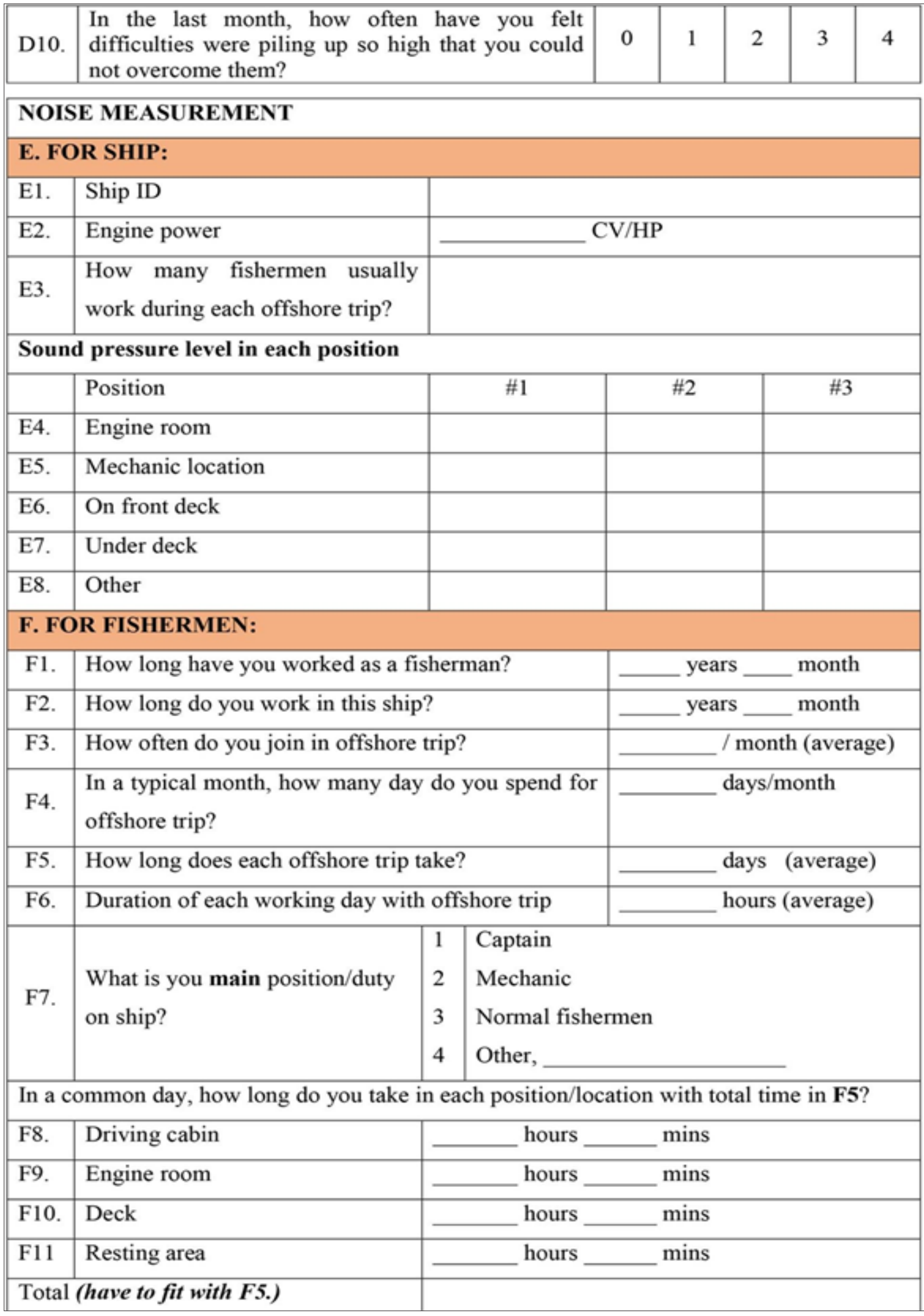




\begin{tabular}{|c|c|c|c|}
\hline F12. & $\begin{array}{l}\text { Do you think you are exposure } \\
\text { with high level of noise? }\end{array}$ & $\begin{array}{l}1 \\
2 \\
3\end{array}$ & $\begin{array}{l}\text { Yes } \\
\text { No } \\
\text { Don't know }\end{array}$ \\
\hline F13. & $\begin{array}{l}\text { Do you know any harmful of } \\
\text { noise? }\end{array}$ & $\begin{array}{l}1 \\
2\end{array}$ & $\begin{array}{l}\text { Yes } \\
\text { No (skip to }\end{array}$ \\
\hline F14. & $\begin{array}{l}\text { What kind of noise's harmful do } \\
\text { you know? (multiple choice) }\end{array}$ & $\begin{array}{l}1 \\
2 \\
3 \\
4 \\
5 \\
6 \\
7\end{array}$ & $\begin{array}{l}\text { Hearing loss } \\
\text { Ear damage } \\
\text { Annoyance } \\
\text { Hypertension } \\
\text { Stress } \\
\text { Others, } \\
\text { Don't know }\end{array}$ \\
\hline F15. & $\begin{array}{l}\text { Which source do you have their } \\
\text { information? (multiple choice) }\end{array}$ & $\begin{array}{l}1 \\
2 \\
3 \\
4 \\
5 \\
6 \\
7\end{array}$ & $\begin{array}{l}\text { TV/radio/Internet } \\
\text { Family } \\
\text { Friend } \\
\text { Colleague as a fishermen } \\
\text { Health staff } \\
\text { Book, newspaper } \\
\text { Other, }\end{array}$ \\
\hline F16. & $\begin{array}{l}\text { Do you know sound standard for } \\
\text { occupational noise? }\end{array}$ & $\begin{array}{l}1 \\
2\end{array}$ & Yes, $_{\text {No }}$ dB \\
\hline F17. & $\begin{array}{l}\text { Overall, do you feel sound level } \\
\text { in this ship is exceed? }\end{array}$ & $\begin{array}{l}1 \\
2 \\
3\end{array}$ & $\begin{array}{l}\text { Yes } \\
\text { No } \\
\text { No idea/Don't know }\end{array}$ \\
\hline F18. & $\begin{array}{l}\text { Do you use any PPE for yourself } \\
\text { protection? }\end{array}$ & $\begin{array}{l}1 \\
2\end{array}$ & $\begin{array}{l}\text { Yes, it is } \\
\text { No }\end{array}$ \\
\hline F19. & $\begin{array}{l}\text { What are your demands on } \\
\text { health care aspect? }\end{array}$ & & \\
\hline F20 & \multicolumn{3}{|c|}{$\begin{array}{l}\text { Do you work at ANOTHER noisy job, such as in construction, farming, a factory, } \\
\text { lawn service, carwash, or other indoor or outdoor job working around loud } \\
\text { equipment or machinery? By noisy job, we mean sounds so loud that you had to } \\
\text { shout or speak in a raised voice to be heard at arm's length. } \\
\qquad \text { Yes } \square \text { No (if no, skip to F21.) }\end{array}$} \\
\hline
\end{tabular}




\begin{tabular}{|c|c|}
\hline & $\begin{array}{l}\text { If you worked a noisy job, please estimate the number of hours you worked in a } \\
\text { typical week: } \\
\text { hours worked per typical week this summer }\end{array}$ \\
\hline \multirow{2}{*}{ F21 } & $\begin{array}{l}\text { Do you live in a noisy place that make you feel annoyance or uncomfortable with it? } \\
\qquad \text { Yes } \square \text { No (if no, stop interviewing.) } \\
\text { If yes, please describe this noisy place and its noise source: }\end{array}$ \\
\hline & $\begin{array}{l}\text { If you live with a noisy place, please estimate duration of exposure in a typical day: } \\
\text { hours exposure per typical day. }\end{array}$ \\
\hline
\end{tabular}

